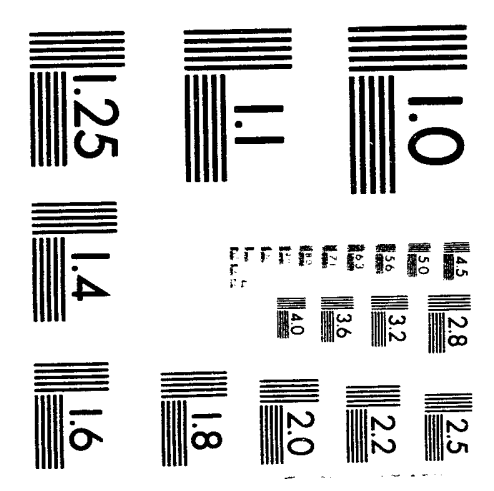




\title{
DIPHONIX - A NEW ION EXCHANGE RESIN FOR THE TREATMENT OF INDUSTRIAL WASTE STREAMS, CONTAMINATED GROUNDWATERS, AND MIXED-WASTES
}

\author{
E. Philip Horwitz \\ Chemical Separations Science Group, Chemistry Division, Argonne National Laboratory
}

Interest in the removal and recovery of heavy (toxic) metal ions from contaminated groundwater, mixed wastes, industrial waste streams, and contaminated drinking water continues to increase as environmental laws become more stringent and permissible discharge limits are lowered.

The Chemical Separations Science Group, led by Dr. E. Philip Horwitz, in collaboration with Prof. Spiro Alexandratos of the University of Tennessee, has synthesized and charezterized a new ion exchange resin that shows considerable potential for the treatment of industrial waste streams and for the treatment of the above-listed waste streams. The new resin contains geminally substituted diphosphonic acid functional groups. The resin is called Diphonix for diphosphonic ion exchange. Alkyl1,1-diphosphonic acids are among the most powerful complexing agents for polyvalent metal ions in aqueous solution, particularly at $\mathrm{pH}<2$. But heretofore, it has not been possible to synthesize resins containing diphosphonic acid groups because of the difficulty of introducing this group into a preformed polymer matrix. The synthesis of Diphonix was accomplished by the copolymerization of a tetralkylvinylidene diphosphonate with styrene, divinylbenzene, and acrylonitrile followed by deesterification of the resultant resin by refluxing with concentrated $\mathrm{HCl}$. During the latter step, the nitrile group is hydrolyzed to a carboxylic acid. The resultant diphosphonic acid resin is then sulfonated to increase its hydrophilicity to significantly improve its metal ion exchange rates.

Distribution ratio data show that Diphonix has impressively strong affinity for actinides in the tri-, tetra-, and hexavalent oxidation states even up to $10 \mathrm{M} \mathrm{HNO}_{3}$ and impressively high affinities for a large number of heavy (toxic) metal ions, e.g., $\mathrm{Mn}, \mathrm{Co}, \mathrm{Ni}, \mathrm{Cu}, \mathrm{Zn}, \mathrm{Cd}, \mathrm{Ng}$, and $\mathrm{Pb}$ from hard water and highly salted solutions.

A patent application on Diphonix has been filed by ARCH Development Corporation and licensed to EIChroM Industries, Darien, IL, and EIChroM has made plans for the commercial production of the new ion exchange resin. Currently, Diphonix is undergoing testing by a major water treatment company and preliminary results are very favorable.

Diphonix resin represents a significant advance in ion exchange synthesis and technology. The initial concept of preparing an ion exchange resin containing the gem-diphosphonic function groups stemmed from a program on thermally unstable complexants that is funded by the Division of Chemical Sciences, Office of Basic Energy Sciences. The initial proof-of-concept of copolymerization of vinylidene diphosphonic acid was also supported by the Division of Chemical Sciences. All subsequent work on Diphonix was supported by the Division of Advanced Energy Projects as will future work aimed at exploiting this new technology.

Hen

aISTMBUTION OF THIS DOCUMENT IS UMLIMITEN 


\title{
DIPHONIX - A NEW ION EXCHANGE RESIN FOR THE TREATMENT OF INDUSTRIAL WASTE STREAMS, CONTAMINATED GROUNDWATERS, AND MIXED WASTES
}

\author{
E. Philip Horwitz
}

\section{Chemical Separations Science Group, Chemistry Division, Argonne National Laboratory}

Interest in the removal and recovery of heavy (toxic) metal ions from contaminated groundwater, mixed wastes, industrial waste streams, and contaminated drinking water continues to increase as environmental laws become more stringent and permissible discharge limits are lowered. Treatment of contaminated water or industrial waste streams has frequently utilized precipitation and ion exchange technologies. However, precipitation will not meet the lower limits and requires excessive quantities of chemicals, and commercially available ion exchange resins do not have high affinities for many of the toxic metals relative to $\mathrm{Ca}$ and $\mathrm{Mg}$.

The Chemical Separations Science Group, led by Dr. E. Philip Horwitz, in collaboration with Prof. Spiro Alexandratos of the University of Tennessee, has synthesized and characterized a new ion exchange resin that shows considerable potential for environmental restoration, for the treatment of industrial waste streams, and for the treatment of alpha-active mixed waste. The new resin contains geminally substituted diphosphonic acid functional groups. The resin is called Diphonix for diphosphonic ion exchange. Alkyl-1,1-diphosphonic acids are among the most powerful complexing agents for polyvalent metal ions in aqueous solution, particularly at $\mathrm{pH}<2$. But heretofore, it has not been possible to synthesize resins containing diphosphonic acid groups because of the difficulty of introducing this group into a preformed polymer matrix. The synthesis of Diphonix was accomplished by the copolymerization of a tetralkylvinylidene diphosphonate with styrene, divinylbenzene, and acrylonitrile followed by deesterification of the resultant resin by refluxing with concentrated $\mathrm{HCl}$. During the latter step, the nitrile group is hydrolyzed to a carboxylic acid. Essentially $100 \%$ of the vinylidene diphosphonate ester is incorporated into the polymer matrix. The copolymerization of the vinylidene diphosphonate ester is a major achievement because of the steric hindrance imposed on the vinylidene group by the diphosphonic group. This difficulty was obviated by using another relatively small monomer (acrylonitrile in our case) as a "carrier" to induce polymerization of the vinylidene diphosphonate. However the resultant diphosphonic acid resin had rather slow metal ion exchange rates because of its hydrophobicity. We discovered that by sulfonation of the diphosphonic acid resin, the hydrophilicity of the resin is increased significantly and the metal ion exchange rates are now comparable to the commercially available macroporous strong acid cation exchange resins (e.g., BioRad AGMP-50). 
The structure of a segment of the polymer matrix of Diphonix is shown in Fig. 1. The resin is actually trifunctional, that is, it contains three functional groups, a gem-diphosphonic group, a carboxylic acid group, and a sulfonic acid group. Early experiments showed definitively that the diphosphonic acid functionality dominates the behavior of the resin towards metal ions. Figure 2 shows the distribution ratio (the amount of activity per gram of resin/amount of activity per ml of solution) of actinides in the tri-, tetra-, and hexavalent oxidation states as a function of the nitric acid concentration. The data show that Diphonix has extraordinarily strong affinities for the actinides in all oxidation states, even in $10 \mathrm{M} \mathrm{HNO}_{3}$. Equally impressive is the ability of Diphonix to extract actinides from high-salt concentrations. Table 1 compares the distribution ratios of U(VI), $\mathrm{Pu}(\mathrm{IV})$, and Am(III) for Diphonix, a commercially available sulfonic acid resin (BioRad AGMP-50), and a monophosphonic-sulfonic acid resin analogous to Diphonix except that a monophosphonic acid functional group replaces the diphosphonic acid group. The aqueous phase is $4 \mathrm{M} \mathrm{NaNO}_{3}-0.1 \mathrm{M}$ $\mathrm{HNO}_{3}$. The data in Table 1 show that Diphonix is superior in its ability to sorb actinides from salt solution. These data translated to a column run would mean that 100 to 1000 more displacement volumes could flow through a Diphonix column before breakthrough occurs than would be the case with the other two resins. The strong retention of actinides even at high acidity and high-salt concentrations is consistent with the behavior of a gem-diphosphonic acid functionality. Conditions for stripping the actinides from Diphonix involve the use of a solution containing either hydroxethane1,1-diphosphonic acid or preferably the more easily destroyed vinylidene-1,1-diphosphonic acid. It is noteworthy that the only efficient stripping agents for Diphonix involve another equally strong complexing agent containing the gem-diphosphonic acid functionality.

Figure 1. Diphonix Polymer Matrix

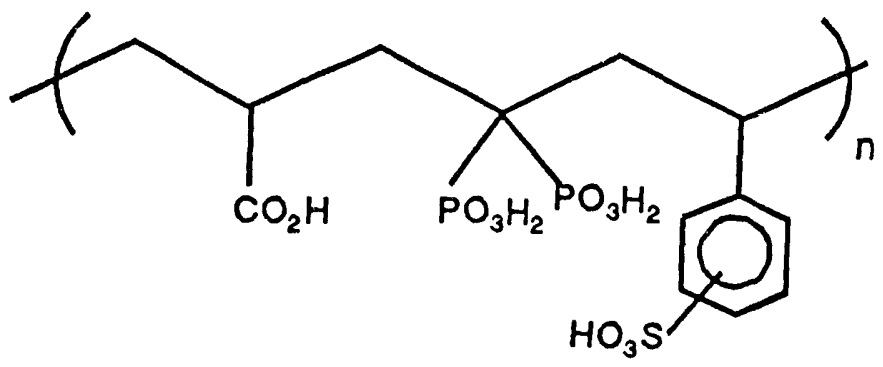

Table 1. Comparison of the Sorption of U, Pu, and Am by Sulfonic, Monophosphonic, and Diphosphonic Acid Ion Exchange Resins

\begin{tabular}{c|ccc}
\hline \multirow{4}{*}{} & \multicolumn{4}{|c}{$4 \mathrm{M} \mathrm{NaNO}_{3}-0.1 \underline{\mathrm{M} \mathrm{HNO}} 3$} \\
\cline { 2 - 4 } $\mathrm{U}$ & Sulfonic & Monophosphonic & Diphosphonic \\
\cline { 2 - 4 } $\mathrm{Pu}$ & $2.9 \times 10^{2}$ & $2.9 \times 10^{3}$ & $2.2 \times 10^{4}$ \\
$\mathrm{Am}$ & $2.6 \times 10^{2}$ & $1.3 \times 10^{3}$ & $2.9 \times 10^{3}$ \\
& $4.8 \times 10^{1}$ & $2.4 \times 10^{1}$ & $5.7 \times 10^{3}$ \\
\hline
\end{tabular}


An important property of an ion exchange resin is its ability to remove heavy (toxic) metals in the presence of high concentrations of $\mathrm{Na}^{+}, \mathrm{Mg}^{2+}$, and $\mathrm{Ca}^{2+}$ ions. Sodium, magnesium, and calcium salts are usually the major constituents of groundwater and industrial waste aside from the toxic metals. Figure 3 compares the uptake of a number of metal ions from $\mathrm{pH} 5$ to 8 with Diphonix and BioRad AGMP-50. Both resins were in their $\mathrm{Ca}^{2+}$ form. In almost every case the distribution ratio is at least 100 times higher with Diphonix than on the commercial sulfonic resin. Table 2 compares the selectivity of Diphonix and IRC-718 relative to $\mathrm{Ca}$ for a number of toxic metal ions. (Rohm \& Haas IRC-718 is the only commercially available all-purpose chelating ion exchange resin.) The superiority of Diphonix is again apparent.

Table 2. Comparison of the Relative Selectivities of Diphonix and of an Iminodiacetic Chelating Resin

\begin{tabular}{ccc}
\hline & $\begin{array}{c}\text { Iminodiacetic Acid } \\
\text { (Amberlite IRC-718 } \\
\text { pH 4 }\end{array}$ & $\begin{array}{c}\text { Diphonix } \\
\text { pH 5 }\end{array}$ \\
\hline $\mathrm{Ca}$ & 1.0 & 1.0 \\
$\mathrm{Mn}$ & 1.2 & $4.1 \times 10^{3}$ \\
$\mathrm{Co}$ & 6.7 & $4.5 \times 10^{2}$ \\
$\mathrm{Ni}$ & 57 & $2.7 \times 10^{2}$ \\
$\mathrm{Cu}$ & $2.3 \times 10^{3}$ & $>10^{3}$ \\
$\mathrm{Zn}$ & 17 & $1.4 \times 10^{4}$ \\
$\mathrm{Cd}$ & 15 & $1.2 \times 10^{3}$ \\
$\mathrm{Hg}$ & $2.8 \times 10^{3}$ & $3.5 \times 10^{3}$ \\
$\mathrm{~Pb}$ & $1.2 \times 10^{3}$ & $9.9 \times 10^{3}$ \\
$\mathrm{U}$ & $4.4 \times 10^{2}$ & $1.3 \times 10^{4}$ \\
\hline
\end{tabular}

Diphonix resin can be readily regenerated by stripping with either moderate concentrations of acid, e.g., $\mathrm{H}_{2} \mathrm{SO}_{4}$ or $\mathrm{HCl}$, or in the case of actinides with strong complexing agents. The resin appears to be quite stable chemically and has essentially the same physical characteristics as commercially available ion exchange resins.

A patent application on Diphonix has been filed by the ARCH Development Corporation and licensed to EIChroM Industries, Darien, IL, and EIChroM has made plans for the commercial production of the new ion exchange resin. Currently, Diphonix is undergoing testing by a major water treatment company and preliminary results are very favorable.

We believe that the Diphonix resin represents a significant advance in ion exchange synthesis and technology. The initial concept of preparing an ion exchange resin containing the gemdiphosphonic function groups stemmed from a program on thermally unstable complexants that is 
funded by the Division of Chemical Sciences, Office of Basic Energy Sciences. The initial proof-ofconcept of copolymerization of vinylidene diphosphonic acid was also supported by the Division of Chemical Sciences. All subsequent work on Diphonix was supported by the Division of Advanced Energy Projects as will future work that will be aimed at exploiting this new technology.

\section{DISCLAIMER}

\footnotetext{
This report was prepared as an account of work sponsored by an agency of the United States Government. Neither the United States Government nor any agency thereof, nor any of their employees, makes any warranty, express or implied, or assumes any legal liability or responsibility for the accuracy, completeness, or usefulness of any information, apparatus, product, or process disclosed, or represents that its use would not infringe privately owned rights. Reference herein to any specific commercial pioduct, process, or service by trade name, trademark, manufacturer, or otherwise does not necessarily constitute or imply its endorsement, recommendation, or favoring by the United States Government or any agency thereof. The views and opinions of authors expressed herein do not necessarily state or reflect those of the United States Government or any agency thereof.
} 


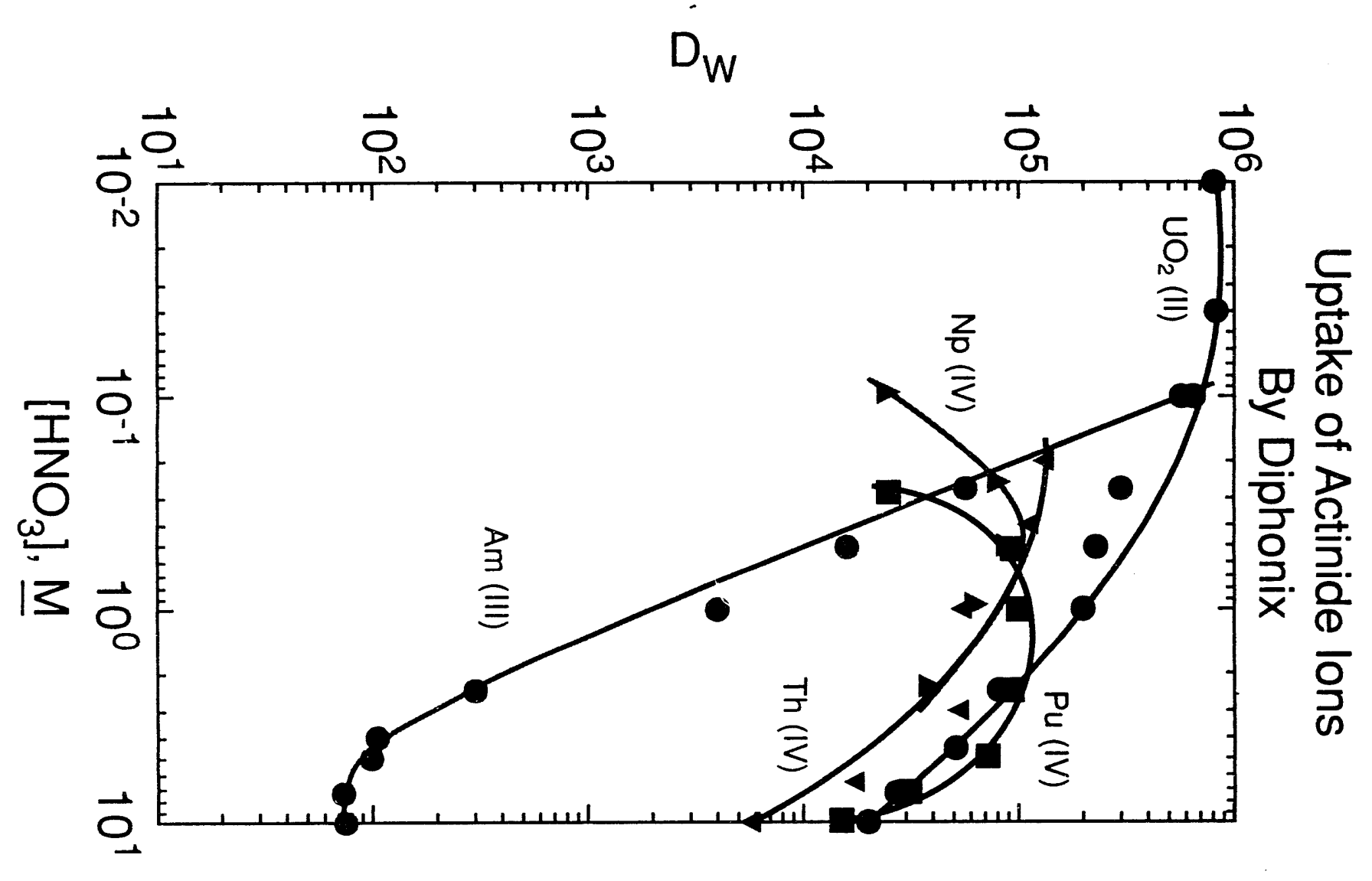


Weight Distribution Ratios of Selected Metal lons Using Ca-Diphonix Resin $\left(25^{\circ} \mathrm{C}\right)$

Diphonix (Ca)

- Bio-Rad AGMP-50 (Ca)
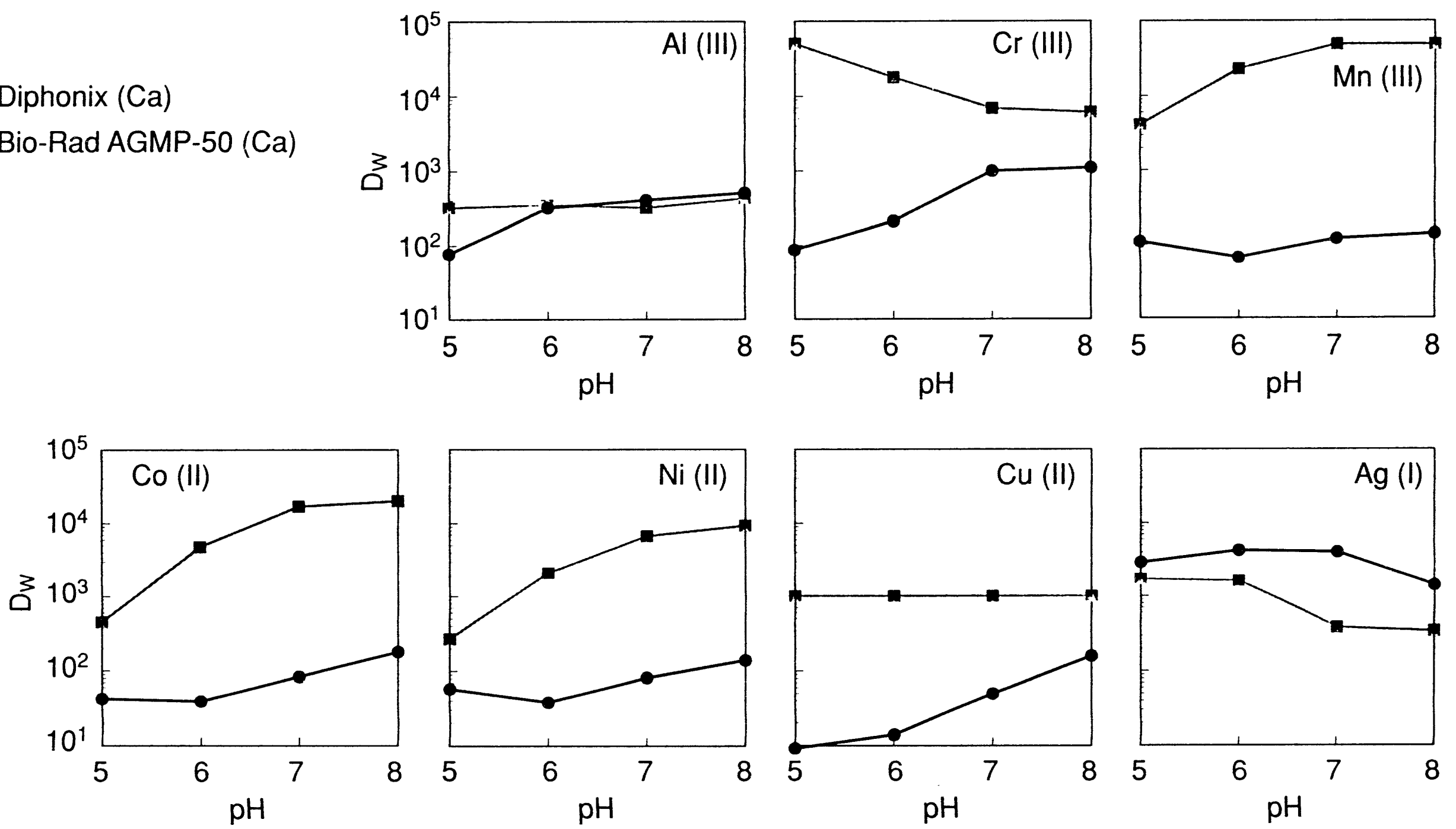


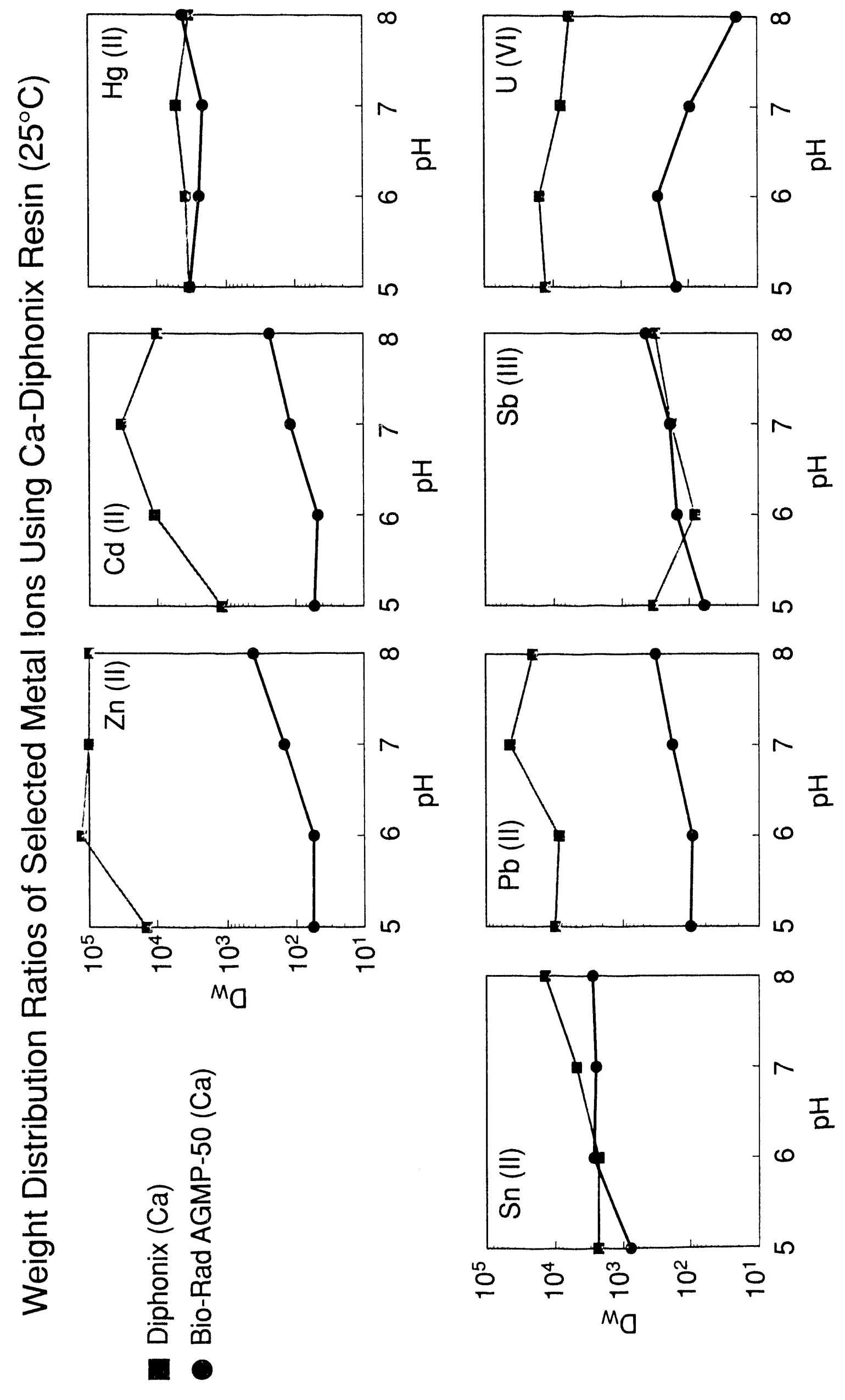



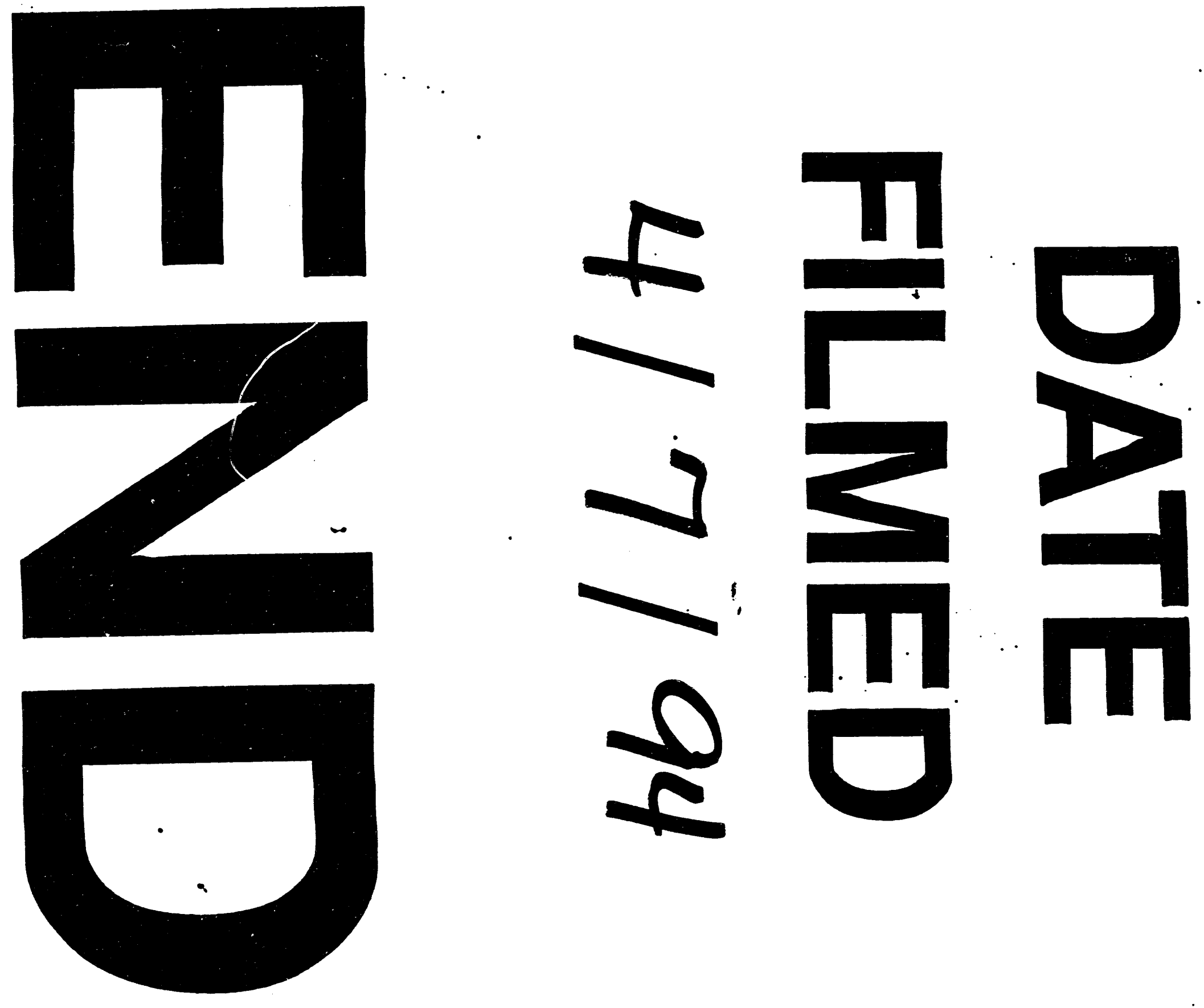


$$
-
$$

